\title{
O gênero miniconto por uma perspectiva bakhtiniana.
}

\author{
Júlio César de Carvalho Santos \\ Universidade de Taubaté - UNITAU
}

\begin{abstract}
Resumo
Este artigo tem como objetivo analisar o gênero discursivo miniconto como instrumento da agilidade de leitura e informação. Os pressupostos teóricos de Bakhtin sobre gênero do discurso e dialogismo fundamentam a análise de quatro minicontos produzidos por autores diferentes. Os resultados da análise sugerem que os minicontos não apresentam as construções narrativas convencionais, permitindo que o leitor faça correlações através do uso de poucas palavras a partir do seu conhecimento prévio.

Palavras-chave: Gêneros discursivos. Minicontos. Dialogismo.
\end{abstract}

\begin{abstract}
The objective of this article is to analyze the flash fiction genre as an instrument of reading speed and information. Bakhtin's proposals concerning genre and dialogism provide the theoretical base for the analysis of four flash fictions by various authors. The results suggest that these flash fictions do not show conventional narrative constructions, which allows readers to make correlations by using a few words from their prior knowledge.

Keywords: Discursive Genres. Flash fictions. Dialogism.
\end{abstract}

\section{INTRODUÇÃO}

Os usuários da internet têm utilizado a escrita, de maneira sucinta, com bastante frequência, e essa prática se tornou comum na elaboração de e-mails, sms (mensagens enviadas via celular) e mensagens pelas redes sociais.

A linguagem escrita utilizada em alguns recursos tecnológicos mais populares se desenvolve através do uso de poucas palavras com o intuito de estabelecer uma comunicação rápida. Diante desse cenário, nos atentaremos a observar o que foi nomeado de miniconto uma narrativa construída com o uso restrito de palavras, que encontramos facilmente nas redes sociais.

Apesar da grande divulgação dos minicontos, principalmente nas redes sociais, esse gênero discursivo ainda não é muito conhecido e divulgado nas escolas. Por isso, com vistas ao ensino de Língua Portuguesa, é salutar estudarmos esse gênero para oferecer mais subsídios ao professor que queira trabalhar com ele em sala de aula, justificando a necessidade de uma análise de sua composição linguística, já que são os minicontos, de certa 
maneira, influenciados pelo contexto histórico - social e pela visão da realidade contemporânea.

Esta pesquisa tem como objetivo geral caracterizar o gênero discursivo miniconto. Especificamente, a pesquisa buscou, num primeiro momento, verificar como o miniconto se caracteriza como gênero; descrever as condições de produção e de circulação do gênero, suas temáticas e seu propósito comunicativo; enfim, buscou caracterizar seus aspectos sociocomunicativos. Num segundo momento, buscou descrever a sua estrutura linguística (organização narrativa) e identificar a escolha do léxico e estilo presentes num corpus de quatro minicontos. Finalmente, a pesquisa buscou verificar as principais relações dialógicas estabelecidas pelos minicontos analisados.

Desses objetivos, resultaram as seguintes perguntas de pesquisa: Quais as características sociocomunicativas do gênero discursivo miniconto? Quais as características linguísticas do gênero discursivo miniconto? Quais as principais relações dialógicas estabelecidas pelos minicontos analisados e que precisam ser compreendidas pelo leitor?

As hipóteses da pesquisa apresentam que o miniconto, pela quantidade de palavras contidas, pode não atender à estrutura de uma narrativa convencional, que geralmente, contém: narrador, personagem, enredo, espaço e tempo. Pela praticidade e rapidez de leitura, acredita-se que a escolha lexical e sintática em um miniconto é diferente daquela em um texto mais longo. No miniconto, esta escolha, influencia diretamente no tamanho do texto e na facilidade de interpretação.

Espera-se que esta pesquisa possa contribuir para a divulgação da leitura de miniconto, e também promova um reconhecimento mais detalhado sobre as características linguísticas presentes nesta narrativa.

Empreenderemos nosso trabalho baseando-nos, principalmente, nos pressupostos teóricos postulados por Bakhtin (2011) sobre gêneros discursivos e dialogismo e os procedimentos para caracterização de um gênero discursivo propostos a partir da teoria de Bakhtin e seu círculo (LIMA, 2014; LOPES - ROSSI, 2006; SOBRAL, 2009). Serão considerados também os autores (FERRAZ, 2007; SPALDING, 2012) que abordam o gênero miniconto em alguns de seus aspectos característicos.

Para realizar este trabalho, utilizamos um corpus de quatro minicontos produzidos por autores diferentes. Estes minicontos, em especial, foram selecionados por terem sido divulgados pela internet em redes sociais, sites ou blogs e por se tratarem de textos destinados a um público acostumado com a praticidade de informação provinda da internet.

\section{FUNDAMENTAÇÃO TEÓRICA}




\section{Gênero discursivo e dialogismo}

Para definir gênero de discurso, a presente pesquisa bibliográfica buscou evidenciar o conceito bakhtiniano do gênero. Segundo Bakhtin (2011), o gênero discursivo é formado por tipos relativamente estáveis de enunciados. Esses enunciados são compostos por três elementos: o conteúdo temático, o estilo e a construção composicional.

Segundo Fiorin (2016, p. 69), “conteúdo temático, estilo e organização composicional constroem o todo que constitui o enunciado, que é marcado pela especificidade de uma esfera de ação". A junção desses elementos está estritamente ligada a um determinado campo da comunicação, por uma condição e finalidade proposta pela atividade humana.

Bakhtin (2011) afirma haver uma heterogeneidade no discurso, que se deve às multiformidades presentes nas atividades humanas; portanto o enunciado, diferentemente das teorias abstratas que consideram a intenção do discurso apenas classificando o gênero em sua estrutura, é analisado a partir da relação que se estabelece no processo comunicativo. Bakhtin (2011) aborda que para cada campo em que a linguagem é utilizada é formado um enunciado que caracteriza o estilo do discurso, portanto, o ato de padronizar o gênero somente pela sua estrutura desconsidera a intencionalidade do autor e o contexto histórico inserido.

Lima (2014), ao analisar o conceito do gênero discursivo na perspectiva bakhtiniana, denota que o gênero para Bakhtin possui um processo de repetição quando ele se remete a enunciados anteriores e um processo de recriação quando o gênero assume novas formas de enunciado. Segundo Lima (2014, p. 37), "Repetição e (re) criação correspondem, portanto, a dois aspectos indissolúveis dos gêneros do discurso que nos ajudam a compreender a existência de uma relativa estabilidade das formas ou dos tipos de enunciados".

Podemos considerar, também, o proposto por Sobral (2009) quando destaca que o enunciado não é apenas um conjunto de palavras, frases e textos descontextualizados; estes são carregados de significados que apresentam temas, estilos e variadas formas de composição. Sobral (2009, p. 88-89) salienta como este processo se insere na relação dos interlocutores:

[..] essa mobilização depende da posição relativa dos interlocutores, das relações enunciativas que o gênero estabelece por meio do discurso e do projeto enunciativo do locutor (em sua constituição por seus interlocutores).O projeto enunciativo é um dispositivo maleável, adaptável, jamais dado de uma vez por todas, mas realizável nos termos de cada conjuntura de produção de enunciados nas quais o locutor realiza seu papel de mediador entre os sentidos socialmente possíveis e os sentidos que efetivamente realiza, sempre relacionalmente e, portanto, em termos valorativos [...] 
Dessa forma, o conceito de gênero apresentado pela teoria bakhtiniana leva em consideração a forma como o enunciado é produzido e sua intencionalidade social e histórica que é percebida pelas concepções e valores que os interlocutores assumem perante o enunciado.

Outro ponto importante a ser destacado nesta pesquisa, direciona - se ao conceito de Dialogismo, que segundo as teorias de Bakhtin e seu Círculo, refere - se a uma relação entre o eu e o outro, assim como exemplifica Melo (2010, p. 236):

O fato de não existir discurso puro e de que o discurso do EU sempre se direciona
para o OUTRO é extensivo para a relação que Bakhtin e seu Círculo estabelecem
com outros conceitos e noções e no próprio método que assumem: não há conceitos
ou noções isolados, estão sempre implicados (dialogados!) com outros; suas obras
resgatam e, num crescente, ampliam e agregam conceitos, noções e teorias. O
diálogo que estabelecem com outros autores, correntes teóricas e discursos é sempre
o ponto de partida para as profícuas reflexões.

Segundo Brait (2011, p. 94-95), o dialogismo, por apresentar essa interação entre o EU e o OUTRO, estabelece um processo comunicativo interdiscursivo, pois as relações sociais influenciam o enunciado. Assim:

[...] o dialogismo diz respeito ao permanente diálogo, nem sempre simétrico e harmonioso, existente entre os diferentes discursos que configuram uma comunidade, uma cultura, uma sociedade. É nesse sentido que podemos interpretar o dialogismo como elemento que instaura a constitutiva natureza interdiscursiva da linguagem.

\section{Procedimentos para caracterização de gênero discursivo}

Cada enunciado poderá produzir diferentes formas de interpretação diante do conhecimento prévio, do cunho social e histórico em que os interlocutores estiverem inseridos. Dessa forma, o discurso presente nestes enunciados, muitas vezes, difere-se das propostas de classificação da tipologia textual.

Segundo Sobral (2009), existem quatro tipos considerados dominantes de tipologia textual: texto descritivo, texto narrativo, texto dissertativo e texto institutivo, que, segundo ele, estabelecem formas estruturais que se combinam. Contudo, o autor salienta:

A identificação dessas formas e de suas combinações, e mesmo sua análise, de modo algum esgotam a inscrição dos textos em discursos e gêneros. Pois o que confere sentido ao texto é sua convocação em discurso/pelo discurso no âmbito de algum gênero, o que implica uma dada esfera de atividades e uma dada maneira social histórica - ideológica de recortar o mundo, ou melhor, a parcela concebível do mundo no âmbito de cada esfera. O que mobiliza esses tipos de texto são as estratégias discursivas, os funcionamentos discursivos, o projeto enunciativo (que vai além das "intenções comunicativas") [...] (SOBRAL, 2009, p. 87). 
Sobre os estudos de caracterização dos gêneros, Lima (2014, p. 38) apresenta quatro dimensões que considera como indissolúveis, a partir do que ele nomeia como dinâmica contraditória existente entre o ato de repetição e recriação.

A primeira dimensão refere-se à relação interlocutiva - trata-se da maneira mutável que o locutor e o interlocutor se veem ao dialogarem. A segunda dimensão é chamada de construção composicional, refere-se ao material verbal ou visual inserido e à maneira como é organizado no enunciado. A terceira corresponde ao conteúdo temático que se dirige ao sentido proposto pelo contexto comunicativo, e a quarta dimensão é direcionada ao estilo, cuja relação prioriza o modo como os falantes adéquam os enunciados a determinados conceitos e circunstâncias comunicativas, com a finalidade de obter objetivos específicos. (LIMA, 2014, p. 38).

Já Lopes - Rossi (2006) sugere seis procedimentos para análise do gênero, salientando que independentemente do gênero discursivo, devem ser priorizadas as características discursivas, composicionais, linguísticas, de estilo e enunciativas.

O primeiro procedimento se refere à escolha de um corpus para análise que contenha fontes e autores diferenciados, a fim de garantir as possibilidades de variação do gênero. $O$ segundo procedimento salienta as condições de produção e de circulação do gênero, estabelecendo qual a função comunicativa, a finalidade do gênero, a temática e as práticas sociais. A autora evidencia que "esses procedimentos dependem muito mais de um conhecimento de mundo sobre como o gênero 'funciona' na sociedade atual do que propriamente da leitura detalhada dos exemplos selecionados” Lopes-Rossi (2006, p.4)

O terceiro procedimento visa identificar as características composicionais presentes no gênero, analisando o conteúdo verbal e não-verbal mediante sua estrutura e suporte. $\mathrm{O}$ quarto procedimento se refere a caracterizar os elementos verbais e não verbais do gênero. Segundo Lopes - Rossi (2006, p. 5), "no caso do texto verbal, deve-se perguntar com que informações começa, como se desenvolve, como termina, qual o padrão geral de organização do texto ou quais as variações possíveis". Quanto a não - verbal, basta analisar como as informações são distribuídas no suporte. O quinto procedimento analisa o conceito das características linguísticas analisando os recursos de vocabulário, pontuação e construção frasal. E por fim, o sexto procedimento apresentado se refere às marcas formais que se destacam no texto. 


\section{O GÊNERO DISCURSIVO MINICONTO}

A partir da pesquisa de alguns autores e da análise de um corpus de quatro minicontos disponibilizados na internet, este trabalho caracterizará o miniconto nos seus aspectos sociocomunicativos, discursivos e linguísticos - textuais.

Para caracterizar o gênero miniconto, buscamos compor os três elementos apresentados por Bakhtin para a composição do gênero: o conteúdo temático, a construção composicional e o estilo que formam o gênero.

\section{Os aspectos sociocomunicativos do miniconto.}

O miniconto provém de outro gênero já bastante conhecido: o conto. Contudo, o conto em sua estrutura se difere do miniconto em alguns aspectos. Dessa forma, exemplificar o gênero miniconto, da mesma forma que se analisa o conto, foge das concepções bakhtinianas de gênero, pois a especificidade contida em um não se parece genuinamente com o que se encontra no outro.

Assim, iniciamos nossa análise sobre o conceito de conteúdo temático na formação do enunciado, que segundo Fiorin (2016, p. 69), "não é o assunto específico de um texto, mas é um domínio de sentido de que se ocupa o gênero". A partir do que já se conhece sobre o gênero conto, somos levados a visualizar o gênero como uma narrativa que conta uma história mais enxuta do que um romance, apresentando temáticas amorosas, maravilhosas, etc.

O miniconto, por sua vez, apresenta características composicionais que identificam o gênero, através de temáticas, que fogem ou não dessa linha provinda do conto. Apresenta uma particularidade narrativa, porém poderá explanar conteúdos que visam refletir, por exemplo, uma situação social contemporânea.

De acordo com o exemplo a seguir, a temática proposta pelo miniconto não é comum nas composições temáticas apreciadas em contos. Não se difunde uma história, em si, mas demonstra uma reflexão acerca de um problema de saúde.

\section{“Alzheimer: conhecer novas pessoas todos os dias". Phil Skversky}

O miniconto, como já dito, não se reduz apenas a contar uma história de maneira mais enxuta, e sim, busca despertar a atenção do leitor com outros objetivos: compor uma crítica social, despertar para uma reflexão a respeito de um determinado assunto ou até mesmo para aguçar a capacidade intelectual do leitor. 


\section{Os aspectos linguísticos - textuais do miniconto.}

O miniconto, de maneira mais genérica, pode ser considerado como uma narrativa. Dessa maneira, inconscientemente, nos remetemos à formação do miniconto buscando eleger os princípios clássicos de um texto narrativo, contendo: narrador, personagem, enredo, tempo e espaço. Contudo, como já mencionado, o miniconto tem como característica conter poucas palavras, e a partir delas, estabelecer um propósito comunicativo.

Nesse entrave de poucos caracteres e de um elenco de cinco elementos que compõem um texto narrativo convencional, não é possível incluí-los à estrutura do miniconto, caracterizando o gênero como um diferencial da estrutura clássica da narrativa.

Outro ponto importante a ser discutido é a escolha do léxico para compor o miniconto. Com o uso restrito de palavras, os autores usam de recursos que permitem agilidade de leitura e ao mesmo tempo são capazes de obter entendimento na constituição do enunciado. Isso acontece muito quando são produzidos os denominados "microcontos". Neles, é comum ocorrer o uso de polissemia (diferentes sentidos para o uso da mesma palavra) e a omissão de conjunções.

Para compor a análise dos aspectos linguísticos - textuais do miniconto, utilizamos um corpus de quatro minicontos retirados de sites da internet, ${ }^{1}$ sendo dois considerados, também, como microcontos. A presente investigação buscará eleger os dois outros elementos que caracterizam o gênero, através da perspectiva bakhtiniana: a construção composicional e o estilo, segundo Fiorin (2016, p. 69):

A construção composicional é o modo de organizar o texto, de estruturá-lo. [...] O estilo diz respeito a uma seleção de meios linguísticos. Ele é, pois uma escolha de certos meios lexicais, fraseológicos e gramaticais em função da imagem do interlocutor e de como se presume sua compreensão responsiva ativa do enunciado.

Segundo Lima (2014), num processo de análise de um gênero faz-se necessária uma explicação mais efetiva do contexto proposto pelo gênero, não se baseando apenas em características descritivas do texto. Dessa maneira, o autor afirma:

\footnotetext{
${ }^{1}$ Fontes consultadas: AUTORES S/A: CONCURSOS LITERÁRIOS. Disponível em: <http://autoressaconcursosliterarios.blogspot.com.br/2013/05/comentarios-e-notas-da-5-fase.html>.

C.E. Manuel de Abreu - Biblioteca Pequeno Príncipe. Disponível em: $<$ http://www.portaleducacao.com.br/pedagogia/artigos/48764/referencias-bibliograficas-tiradas-na-internet-comocolocar-no-trabalho.
} 
[..] apenas uma análise científica especial pode tornar patentes as diferenças internas que se escondem por trás e são escondidas pelas similaridades externas. Nesse caso, o objetivo da análise que pratica a explicação e não apenas a descrição é identificar as diferenças internas dessas atividades. (LIMA, 2014, p. 39).

\section{Exemplo 1:}

"Fui me confessar ao mar." "O que ele disse?" "Nada."

Lygia Fagundes Telles

O exemplo 1 estabelece um diálogo; mesmo sem uma inserção de um contexto antecedente, o leitor já estabelece por conhecimento prévio de que se trata de uma conversa. Aqui, não se deixa clara a presença de um narrador, o texto não identifica a priori quem conta a história, o fato já se produz através das falas das personagens.

Lopes - Rossi (2006) salienta a importância de que, para se estudar um gênero discursivo, é prudente analisar as construções frasais, o tom e o vocabulário inserido, o que a autora nomeia como um procedimento que se refere ao conhecimento das características linguísticas. O que chama a atenção na composição deste microconto é a resposta dada à pergunta feita pelo segundo personagem. Ao responder "nada", o leitor poderá estabelecer duas intencionalidades para o recurso polissêmico utilizado pela autora. Inicialmente, o leitor poderá interpretar a palavra nada se referindo ao verbo nadar; em se tratando de mar, seria prudente essa interpretação. Logo, também acionaria uma resposta às confissões da personagem, estabelecendo uma comunicação pela personificação do mar.

Podemos analisar, também, a palavra nada como um advérbio de negação. Dessa maneira, quebra-se a expectativa do contexto e faz com que o leitor não aprecie o enredo proposto. Para que o leitor possa compreender qual foi a intenção da autora ao utilizar a palavra nada, é necessário que este seja capaz de perceber a ambiguidade contida no texto. Caso contrário, ao analisar a palavra apenas com um só sentido o propósito comunicativo dinâmico do microconto se desfaz.

Outro aspecto importante a ser analisado sob o ponto de vista do enunciado está na pergunta feita pelo suposto segundo personagem. Ao perguntar: "O que ele disse?" há na intencionalidade da pergunta que o personagem já sabe quais são as confidências feitas ao mar, pois caso contrário, a pergunta seria direcionada a saber quais eram essas confidências, e não, qual teria sido a resposta do mar. Isso estabelece o que Bakhtin propõe como Dialogismo, que segundo Fiorin (2016, p. 27), 
[..] é o modo de funcionamento real da linguagem, é o princípio constitutivo do enunciado. Todo enunciado constitui-se a partir de outro enunciado, é uma réplica a outro enunciado. Portanto, nele ouvem-se sempre, pelo menos duas vozes. Mesmo que elas não se manifestem no fio do discurso, elas estão aí presentes.

\section{Exemplo 2}

"Alzheimer: conhecer novas pessoas todos os dias"

\section{Phil Skversky}

O segundo exemplo exige a interpretação do leitor sobre o conceito de Alzheimer. Pela utilização dos dois pontos após a palavra, de certo modo, se espera uma explicação voltada aos conceitos científicos que explanariam o que significa o termo proposto, ou seja, como se trata de uma patologia, o leitor espera ler palavras que determinem o significado do termo através de um ideal científico, geralmente proposto por textos de caráter dissertativo.

Analisando a estrutura do miniconto, o pequeno texto não apresenta narrador, personagem, tempo e espaço, contudo há um contexto inserido que faz com que o leitor desperte em sua memória, o que uma doença como o Alzheimer pode trazer. Desse modo, propomos analisar que o leitor já conhece que o paciente acometido por esta doença tem uma perda de memória agressiva e identifica o propósito do autor em usar uma expressão menos teórica.

Como no exemplo anterior, o autor utiliza uma marca enunciativa que caracteriza o propósito de um microconto, que nada mais é do que expressar em poucas palavras um contexto, levando o leitor a uma análise interpretativa, buscando resgatar o seu conhecimento de mundo para que a compreensão possa ser efetiva. Caso contrário, o leitor não compreenderá a ideia expressa. Nesse caso, em especial, o leitor precisa dialogar com outro enunciado, assim como Bakhtin nos apresenta. O leitor, para compreender o contexto deverá saber que o Alzheimer é uma doença que causa a perda de memória, portanto, mesmo a pessoa sendo vista todos os dias pode ser considerada, para o doente, alguém desconhecido.

Assim como evidencia Lopes - Rossi (2006) sobre a importância de uma leitura mais detalhada do corpus dos textos para a caracterização do gênero, podemos destacar que o autor de um miniconto usa de outras vozes para acionar a imagem proposta pelo enunciado, assim como seleciona palavras e pontuações que permitem caracterizar o gênero como um jogo estratégico de recursos de combinação sintática e morfológica. 


\section{Exemplo 3}

\section{Fonte dos desejos}

Na Fontana Di Trevi, jogou uma moeda por cima do ombro esquerdo, esticando com vírgulas, em tom de deboche, um pedido - mantra. "Que eu fique eternamente jovem, que meu peso nunca aumente, que meus seios jamais caiam" Amanheceu manequim.

\section{Anima Brevis}

No terceiro exemplo, o miniconto possui características bem marcadas de uma estrutura narrativa. Inicialmente, é possível notar a presença de um narrador - observador. O lugar também fica evidenciado já na primeira parte do texto (Na Fontana Di Trevi), que se trata, como o próprio título apresenta, de uma fonte dos desejos.

Há também uma personagem feminina no texto, o leitor pode perceber pelas características físicas e comportamentais que o autor apresenta. $\mathrm{O}$ pedido feito à fonte de permanecer sempre jovem, magra e que os seios jamais caiam, já indicia a personagem numa esfera feminina.

Ao contrário dos outros exemplos apresentados, o texto Fonte dos desejos é mais próximo de uma narrativa convencional do que os outros. O leitor não precisa fazer tantas correlações para compreender o enredo, porém, o final da história permite uma interpretação mais cuidadosa, quando o autor finaliza o texto como: "Amanheceu manequim".

O texto vai despertar no leitor, assim como nos exemplos anteriores, o seu conhecimento prévio a respeito, por exemplo, da busca constante pela beleza. O autor, portanto, realiza uma crítica a esse comportamento, pois a única forma de ser completamente perfeita a vida toda é se tornar um manequim, que nada mais é do que um ser inanimado que vai conter as mesmas formas físicas por tempo indeterminado.

O que de fato fica evidenciado neste contexto é analisar a palavra manequim como o resultado do pedido feito pela mulher. Não simplesmente pelo fato da transformação em si, mas pelo uso dinâmico do termo para posicionar o leitor quanto à opinião do autor em relação ao tema. 


\section{Exemplo 4}

\section{O último a saber}

Parecia ser a sua sina eterna. Novamente foi o último a saber. Ao entrar perambulando no bar, onde alguns entristecidos amigos saciavam a sede, soltou um grito ao perceber que só faltava a sua sombra na parede.

Pseudônimo: Mutante

No quarto exemplo, o autor joga com um realismo fantástico, despertando no leitor um certo impacto sofrido pelo personagem ao descobrir a própria morte. O leitor mais interado com a Literatura, por sua vez, poderá se remeter a outras histórias com essa temática, assim como no livro Memórias Póstumas de Brás Cubas, de Machado de Assis. Essa interação com outros contextos justifica o que Fiorin (2016) retrata sobre a perspectiva bakhtiniana de um enunciado fazer referência a outro, que se desperta pelo conhecimento prévio do leitor.

Pela sequência dos fatos e organização do texto, o miniconto atribui características narrativas convencionais, como: narrador, personagem, tempo, espaço e enredo. Notamos a presença de uma sequência rítmica na leitura do texto com palavras que soam rima: saber / perceber; entrar / bar; sede / parede.

Com esse recurso de sonoridade, o autor não apenas cria uma história, como desenvolve um procedimento de leitura do miniconto parecido com uma leitura poética. Essa possibilidade de (re) criação, assim como menciona Lima (2014), não distancia o texto de um formato característico narrativo, contudo, produz no leitor uma sensação diferenciada de leitura, até prazerosa. Os gêneros, assim como afirma Lima (2014, p.39):

[...] são entidades que se encontram em constante mutação, não podendo ser estudados, em sua essência, de um ponto de vista meramente sincrônico, o qual perde de vista a tão importante dimensão genérica da (re) criação.

O anúncio da morte da personagem desperta no leitor uma referência imagética. Observamos que o autor não usa a palavra morte, mas uma imagem para exemplificar o ocorrido. Dessa forma, pelo conhecimento de mundo do leitor ele atribui a ausência de sombra da personagem à morte. Tratando-se de um texto enxuto como este, o autor utiliza referenciais imagéticos para despertar o imaginário do leitor, não se prendendo a detalhes de como o infortúnio aconteceu. 


\section{CONCLUSÃO}

A análise dos dados permite concluir que o miniconto surgiu como uma nova forma de leitura prática e repleto de características diferentes de um conto tradicional. Apesar de ser considerado um texto narrativo, o miniconto se comporta com uma determinada liberdade em sua essência separando-se de padrões preestabelecidos.

As temáticas propostas são influenciadas por diversos meios, sejam eles sociais, históricos, ou até mesmo convencionais de cunho bucólico ou amoroso. O que de fato desperta a criatividade proposta em seu contexto é despertar no leitor o uso de inferências e promover como propósito comunicativo uma leitura rápida, repleta de indícios ideológicos que influenciam o leitor tanto em sua capacidade de compreensão quanto em seu posicionamento.

A organização narrativa, não é de fato, algo a ser valorizado dentro de um miniconto. O autor é capaz de inserir o leitor em um determinado enredo sem a necessidade de apresentar indícios clássicos que são presentes em um texto narrativo. O leitor, pela sua capacidade de inferir no texto, poderá compreender e articular as ideias presentes sem a necessidade de conferir se o texto apresenta um espaço ou um tempo, por exemplo.

Os recursos linguísticos, presentes nessa composição textual, são recursos que visam valorizar o conteúdo exposto, permitindo que o leitor possa discutir com o texto qual de fato é o posicionamento do autor a respeito de determinado assunto. Assim, como exemplificado neste trabalho, o uso de polissemia, por exemplo, pode levar o leitor a compreender determinado desfecho, a partir do que para ele seria mais viável. Essa possível dupla interpretação, além de instigar o leitor, valoriza a escolha lexical e a intenção exposta pelo autor em gerar um certo desconforto no leitor para saber de fato qual seria a maneira mais acertada de interpretar o contexto.

Ao analisar as relações dialógicas necessárias para a compreensão temática dos minicontos, notou-se uma necessidade de o leitor desse tipo de texto ter, em alguns casos, conhecimento prévio necessário para ser capaz de compreender a proposta elaborada pelo autor. O miniconto, pela quantidade de caracteres, tem como objetivo explanar determinado conteúdo temático de maneira sucinta. Dessa maneira, o autor busca no leitor, de certo modo, que ele seja capaz de relacionar textos, pois muitas vezes, para que a compreensão seja efetiva, o leitor necessita resgatar do seu conhecimento de mundo informações importantes para que o entendimento do texto não fique comprometido. 
A presente pesquisa, de certo modo, espera ter contribuído para que a leitura de minicontos seja vista a partir de uma outra ótica, não apenas como um recurso prático de leitura, mas como objeto de estudo para elevar a capacidade de interpretação e leitura de mundo para as aulas de Língua Portuguesa.

\section{REFERÊNCIAS}

AUTORES S/A: CONCURSOS LITERÁRIOS. Disponível em:

$<$ http://autoressaconcursosliterarios.blogspot.com.br/2013/05/comentarios-e-notas-da-5fase.html>. Acesso em 28 de jul. 2016.

BAKHTIN, Mikhail M. Os gêneros do discurso. In. Estética da criação verbal. Trad. Paulo Bezerra. São Paulo: Martins Fontes, 2011. p.261-306.

BRAIT, B. Bakhtin e a natureza constitutivamente dialógica da linguagem. In: BRAIT, B. Bakhtin, dialogismo e construção de sentido. 2. ed. São Paulo: Editora da Unicamp, 2005.

C.E. Manuel de Abreu - Biblioteca Pequeno Príncipe. Disponível em:

$<$ http://www.portaleducacao.com.br/pedagogia/artigos/48764/referencias-bibliograficastiradas-na-internet-como-colocar-no-trabalho >. Acesso em 29 de jul. 2016.

FERRAZ, Geraldo G. As histórias de um parágrafo. Lingua Portuguesa, São Paulo. Ano 2, n. 21, 2007. p. 38-39.

FIORIN, J.L. Introdução aos pensamentos de Bakhtin. 2. ed. São Paulo: Contexto, 2016.

LIMA, Anselmo Pereira. Procedimentos teórico-metodológicos de estudo de gêneros do Discurso: atividade e oralidade em foco. In: BRAIT, B.; MAGALHÃES, A. S. (Org.). Dialogismo: teoria e(m)prática. São Paulo: Terracota, 2014.

LOPES-ROSSI, M. A. G. Procedimentos para estudo de gêneros discursivos da escrita. Revista intercâmbio, volume XV. São Paulo: LAEL/PUC-SP, 2006.

MELO, Roseneide de. O discurso como reflexo e refração e suas forças centrífugas e centrípetas. In: PAULA, L.; STAFUZZA, G. (Org.). Círculo de Bakhtin: teoria inclassificável. Campinas: Mercado de Letras, 2010. p. 235-264.

SOBRAL, A. Ver o texto com os olhos do gênero: uma proposta de análise. Bakhtiniana, São Paulo, v. 1, n. 1, 1o sem. 2009. p. 85-103

SPALDING, M. Presença do miniconto na literatura brasileira. Conexão Letras, Porto Alegre.v. 7,n. 8, 2012. Disponível em:

http://seer.ufrgs.br/index.php/conexaoletras/article/view/55443/33705 Acesso em 28 jun. 2016. 


\section{O AUTOR}

Júlio César de Carvalho Santos é mestrando em Linguística Aplicada na Universidade de Taubaté (UNITAU), professor efetivo de Língua Portuguesa na rede municipal e estadual de São Paulo e concluinte do curso de pós-graduação em Planejamento, Implementação e Gestão de Educação a Distância pela Universidade Federal Fluminense (UFF).

E-mail: jucercarvalho@hotmail.com 
